\title{
ENGEVISTA
}

Página da revista: http://www.uff.br/engevista/seer/

\section{DORT'S: doenças osteomusculares relacionadas aos trabalhadores de pedreira}

\author{
Andressa Souza Fernandes ${ }^{1}$ \\ Renata Rodrigues Campos ${ }^{2}$ \\ Fábio Luiz Fully Teixeira ${ }^{3}$ \\ Rosana Therezinha Queiroz Oliveira ${ }^{4}$ \\ Thais Cristina Vargas Garrido 5
}

DORT'S: musculoskeletal diseases related to quarry workers

\begin{abstract}
Resumo: As Lesões por Esforços Repetitivos (LER) ou como designados mais recentemente como Distúrbios Osteomusculares Relacionados do Trabalho (DORT). Os trabalhadores de pedreira, em especial, se submetem todos os dias a trabalhos que exigem muito esforço, por isso são mais suscetíveis a desenvolver algum tipo de DORT, principalmente se não tiver acesso a equipamentos adequados de prevenção a atividade física exercida. Chegou-se a conclusão que os trabalhadores de pedreiras desconhecem a doença DORT e os meios de prevenção, o que aponta para a necessidade de todos os trabalhadores conhecerem a importância da postura correta, do cuidado ao praticar esforço e a utilização de equipamentos de proteção e a fim de amenizar a incidência de casos. O objetivo deste trabalho teve a finalidade de identificar o conhecimento dos trabalhadores de pedreira sobre a doença ocupacional (DORT) e seus mecanismos de prevenção.
\end{abstract}

Palavras-chave: DORT; LER; Trabalhador, Pedreira.

${ }^{1}$ UNIG - Universidade Iguaçu

${ }^{2}$ UNIG - Universidade Iguaçu

${ }^{3}$ UNIG - Universidade Iguaçu

${ }^{4}$ UFF - Universidade Federal Fluminense

${ }^{5}$ UERJ - Universidade do Estado do Rio de Janeiro 
ISSN: $1415-7314$

ISSN online: $2317-6717$

\begin{abstract}
Repetitive Strain Injuries (RSI) or as more recently referred to as Work-Related Musculoskeletal Disorders (DORS). Quarry workers, in particular, undergo daily work that requires a lot of effort, so they are more likely to develop some type of DORS, especially if they do not have access to adequate equipment to prevent physical activity. It was concluded that the workers of quarries are not aware of the DORT disease and the means of prevention, which points to the need for all workers to know the importance of correct posture, care when exerting and the use of protective equipment and in order to reduce the incidence of cases. The objective of this work was to identify the knowledge of the quarry workers about occupational disease
\end{abstract} (DORS) and its prevention mechanisms.

Keywords: DORS; RSI; Worker, Quarry. 


\section{Introdução}

As Lesões por Esforços Repetitivos (LER) ou como designados mais recentemente como Distúrbios Osteomusculares Relacionados do Trabalho (DORT) há muito tempo vêm atormentando os trabalhadores, mas foi no século XVIII (1713) que o médico Bernardo Ramazzini iniciou seus estudos em seus pacientes que demonstravam ter problemas decorrentes do trabalho (Nogueira \& Benetti, 2016). Ramazzini identificou dessa forma que os trabalhadores que exerciam muitas tarefas que dependiam da escrita acabavam por ter seus músculos afetados, como os secretários e escrivães do príncipe. Após essa descoberta, o pai da medicina ocupacional, alegou que a doença 'câimbra do escrivão' como ele denominou, era ocasionado pelo uso repetitivo da mão (Ramazzini, 2016).

Mais tarde, precisamente no ano de 1908 na Inglaterra, com o surgimento do telegrama, os telegrafistas também passaram a apresentar LER/DOR, denominada na época de "câimbra do telegrafista; tendo sido considerada pela coroa Britânica como passível de indenização (Ramazzini, 2016).

Surge então a sigla LER (Lesões por Esforço Repetitivos) que nasceu da necessidade de juntar um conjunto de doenças em uma só sigla; que são: dor crônica, dormência e formigamento nos membros, coluna e músculos (Novaes, 2017).

No Brasil, a LER/DORT foi introduzida em 1986 no I Encontro Estadual de Saúde de Profissionais de Processamento de Dados, pelo médico Mendes Ribeiro, encontro de médicos no Rio Grande do Sul (Novaes, 2017).

Mas, com o passar do tempo, a previdência social decidiu mudar a etimologia LER para DORT, por alegar que nem sempre o trabalhador com DORT lesiona, machuca e nem aparenta ter algo, por esse motivo em 1998 fica definido o termo DORT (Teixeira, 2007).

O nome dado para o grupo de afecções foi modificado inúmeras vezes em diversos países, o que demonstra a procura de um nome que conceitue de forma mais ampla e clara essas afecções. No início da década de 1980, no Brasil, o termo tenossivite passou a ser usado para rotular casos de dor e desconforto nos membros superiores (MMSS) e os relacionados ao trabalho (Monteiro \& Bertagni, 2000). O INSS, em 1987, adotou LER como denominação desses casos. Todavia, continuará a ser uma denominação muito limitada, pois as diversas lesões e limitações funcionais aconteciam muitas das vezes em fases tardias, dificultando a recuperação. Portanto, mais recentemente, o termo DORT, apesar de vago, passou a ser mais propício para o diagnóstico e classificação de afecções (Teixeira, 2007).

Pode se dizer que a DORT é uma doença que acomete vários trabalhadores, por este motivo no ano de 2000 passou-se a ter uma data para a conscientização que é o dia 28 de fevereiro; 
denominado como o dia internacional de Combate às Lesões por Esforços Repetitivos ou Distúrbios Osteomusculares Relacionados do Trabalho (DORT). Hoje é uma das doenças que afeta vários trabalhadores, afastando do trabalho e algumas vezes o deixando impossibilitado de trabalhar por tempo indeterminado (Barbosa et al, 2007).

Os trabalhadores de pedreira, em especial, se submetem todos os dias a trabalhos que exigem muito esforço, por isso são mais suscetíveis a desenvolver algum tipo de DORT, principalmente se não tiver acesso a equipamentos adequados de prevenção a atividade física exercida. O objetivo deste trabalho teve a finalidade de identificar o conhecimento dos trabalhadores de pedreira sobre a doença ocupacional (DORT) e seus mecanismos de prevenção.

\section{Método}

Foi realizada pesquisa qualiquantitativa com observação participante e aplicação de questionário semiaberto aos trabalhadores de uma pedreira no município de Pádua, Estado do Rio de Janeiro. A Abordagem aos trabalhadores foi realizada mediante a aproximação qualitativa, por meio da utilização de linguagem coloquial, com objetivo de favorecer o entendimento. Após o aceite em participar da pesquisa, foi assinado pelo trabalhador o termo de consentimento livre e esclarecido (TCLE), que garante, entre outros aspectos, o sigilo sobre a identidade dos participantes.

O questionário aplicado aos 16 trabalhadores da pedreira era composto por 13 questões que abordavam aspectos sócios funcionais e conhecimentos sobre DORT (idade; tempo de trabalho na função; carga horária semanal; problemas como dor, formigamento ou dormência em alguma parte do corpo; caso sim, em qual parte do copo; impedimento ou dificuldade de realizar algum tipo de tarefa por sentir dor; qualidade no desenvolvimento do trabalho; horas-extras; pagamento por produção; utilização de equipamento de segurança, caso sim, qual equipamento que utiliza; sabe o que é LER/DORT; conhece alguém na pedreira que tem está doença).

Os diferentes pontos da pedreira em questão foram fotografados (Figura 1 e 2) com o consentimento do supervisor, mediante compromisso de não divulgar nomes dos trabalhadores e o nome e o endereço da pedreira em questão. Os blocos de pedra pesavam, em geral, de 35 a 50 quilos cada um.

Foi utilizado EPI INFO 7 para análise de correlação e significância dos dados do questionário. 
ISSN: $1415-7314$

ISSN online: 2317-6717

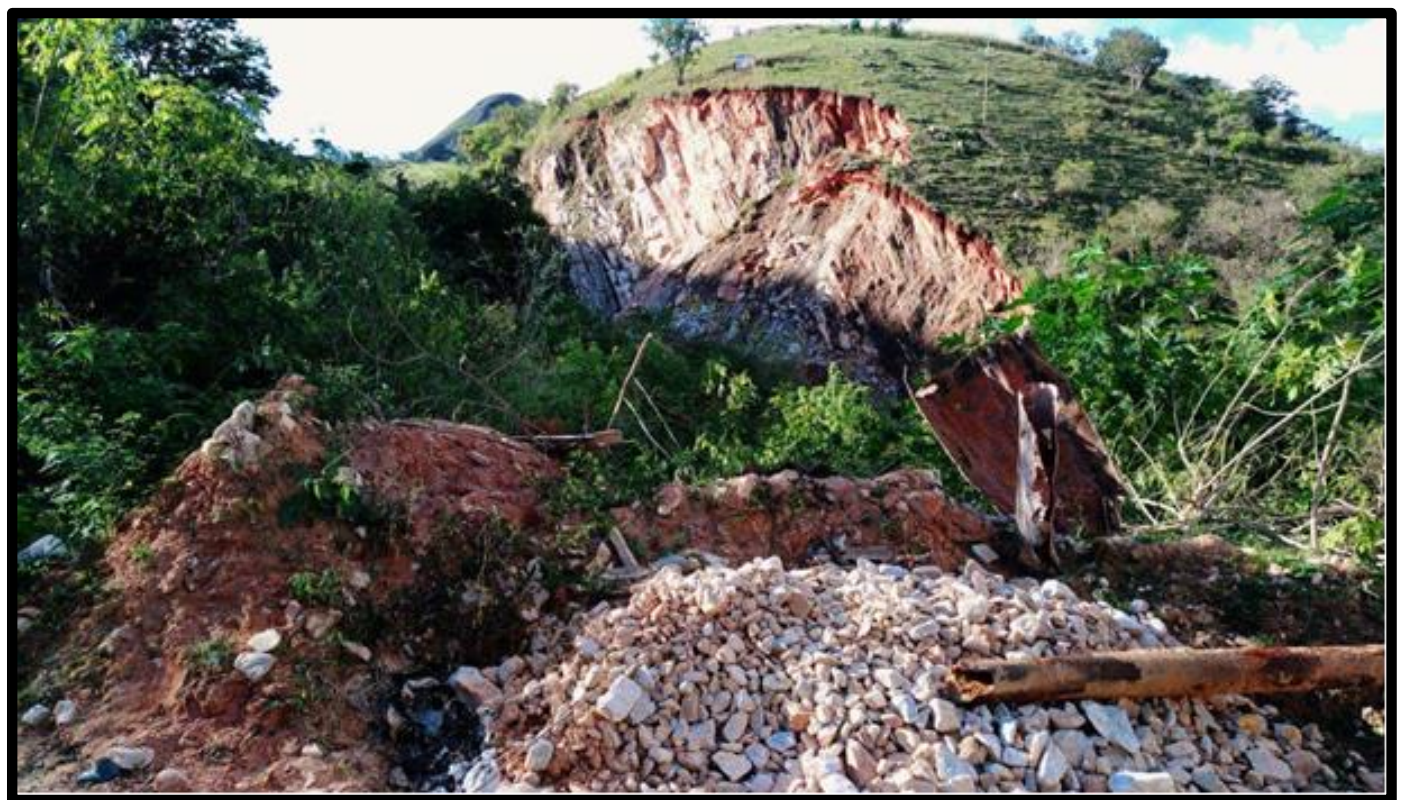

Figura 1: Local de retirada de rochas.

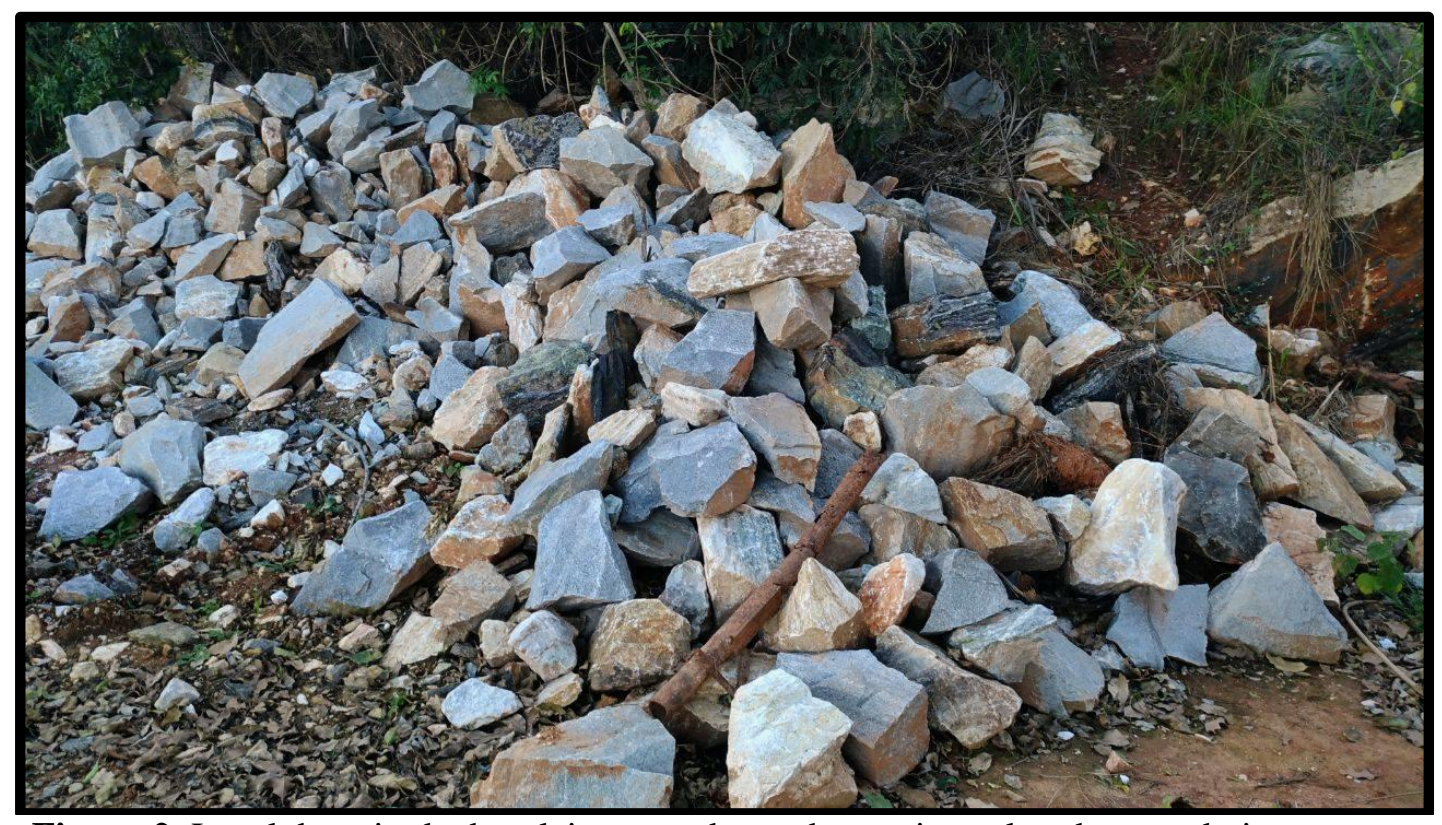

Figura 2: Local de retirada de calcita, uma das rochas mais explorada na pedreira.

\section{Resultados}

Os resultados do questionário mostrou que os trabalhadores possuíam de 18 a 58 anos (Questão_1), sendo a maioria $(75 \%, \mathrm{n}=12)$ com mais de 30 anos de idade e 56\% (n=9) possuíam 20 ou mais anos de tempo de trabalho (Questão_2).

Os trabalhadores que possuíam menos de 20 anos de tempo de trabalho $(43,75 \%$, n=7) estavam na faixa etária de 32 a 18 anos (Figura 3). 


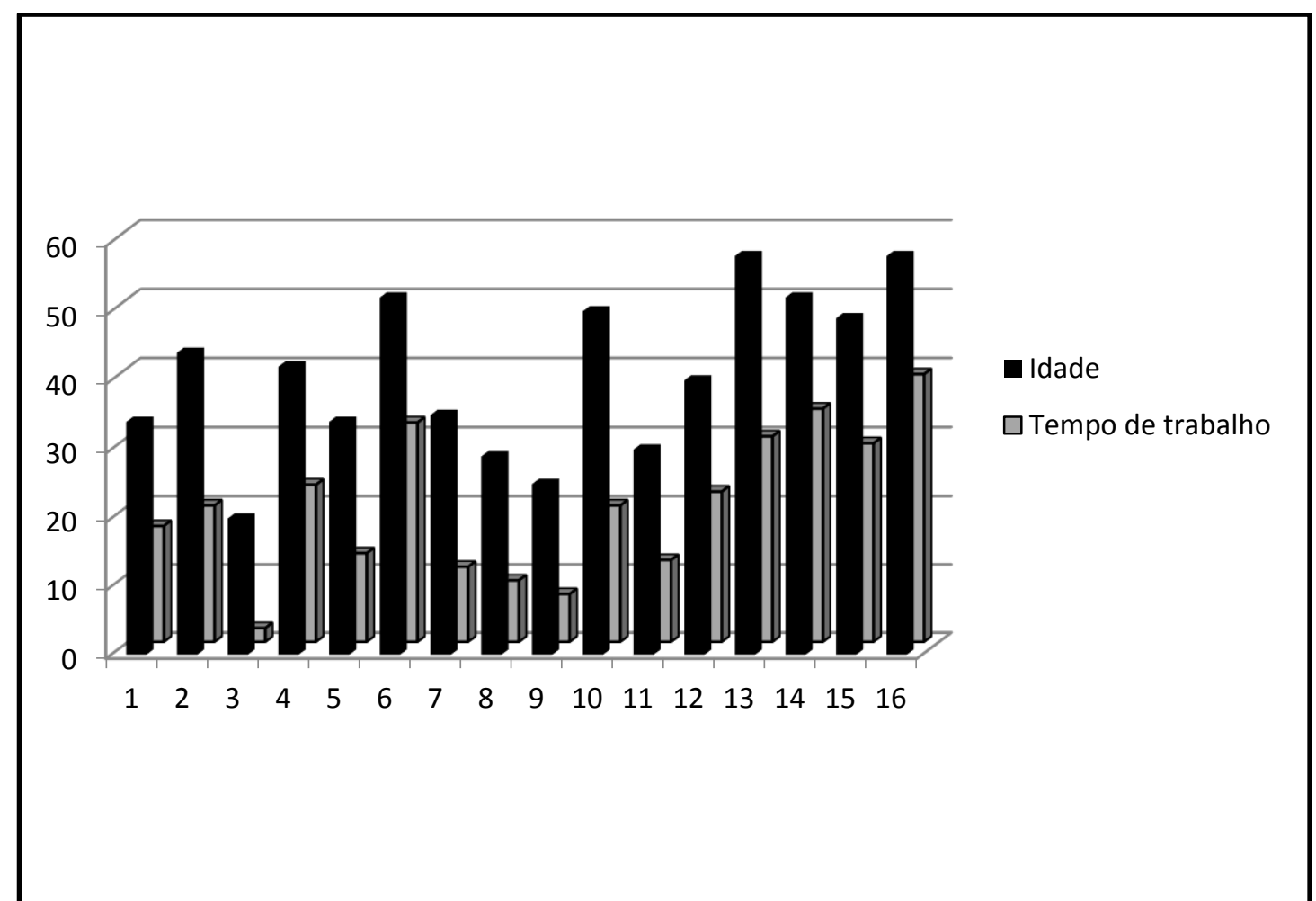

Figura 3: Relação entre idade e tempo de trabalho dos trabalhadores da Pedreira

Os trabalhadores quando questionados quanto à carga horária semanal (CHS) trabalhada (Questão_3), 100\% $(n=16)$ declararam trabalhar 48 horas semanais (Figura 4).

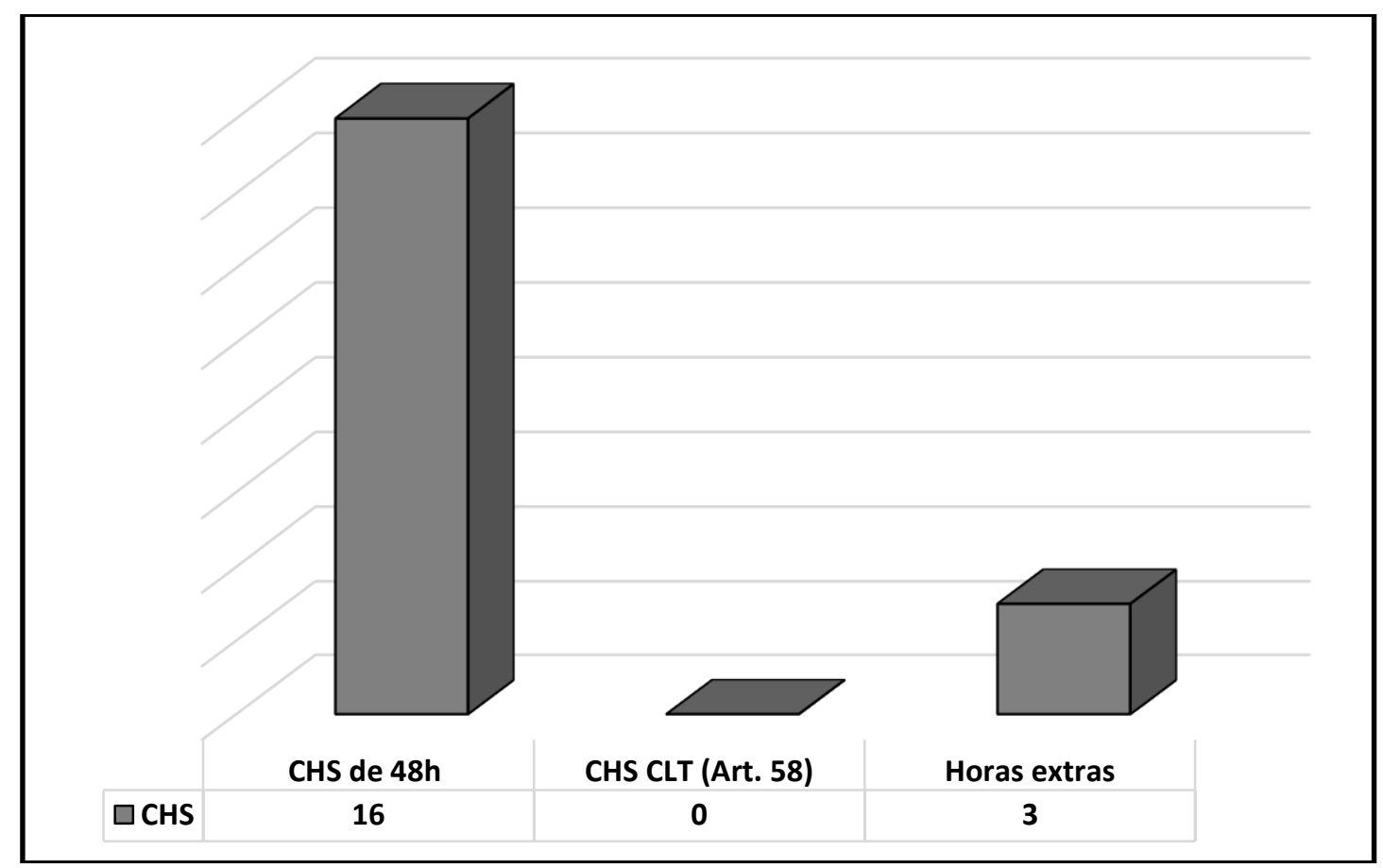

Figura 4: Relação carga horária de trabalho e horas extras recebidas. 
No entanto, apenas $18,75 \%(\mathrm{n}=3)$ responderam que recebiam horas extras (Questão_9) (Figura 4).

Dos 16 respondentes, três $(18,9 \%)$ declarou sentir dor nas costas (Questão_4_5), ter dificuldade para realizar suas tarefas (Questão_6), não recebiam pagamento por produção (Questão_8) (Figura 5).

Quando perguntados sobre a utilização de Equipamento de Proteção Individual (EPI), 100\% (n=16) responderam usar EPI (Questão_10) (Figura 5).

Em relação às questões 12 e 13, todos os trabalhadores $(100 \%, n=16)$ declararam não saber o significado de DORT e consequentemente, desconheciam se algum trabalhador da Pedreira sofria dessa doença (Figura 5).

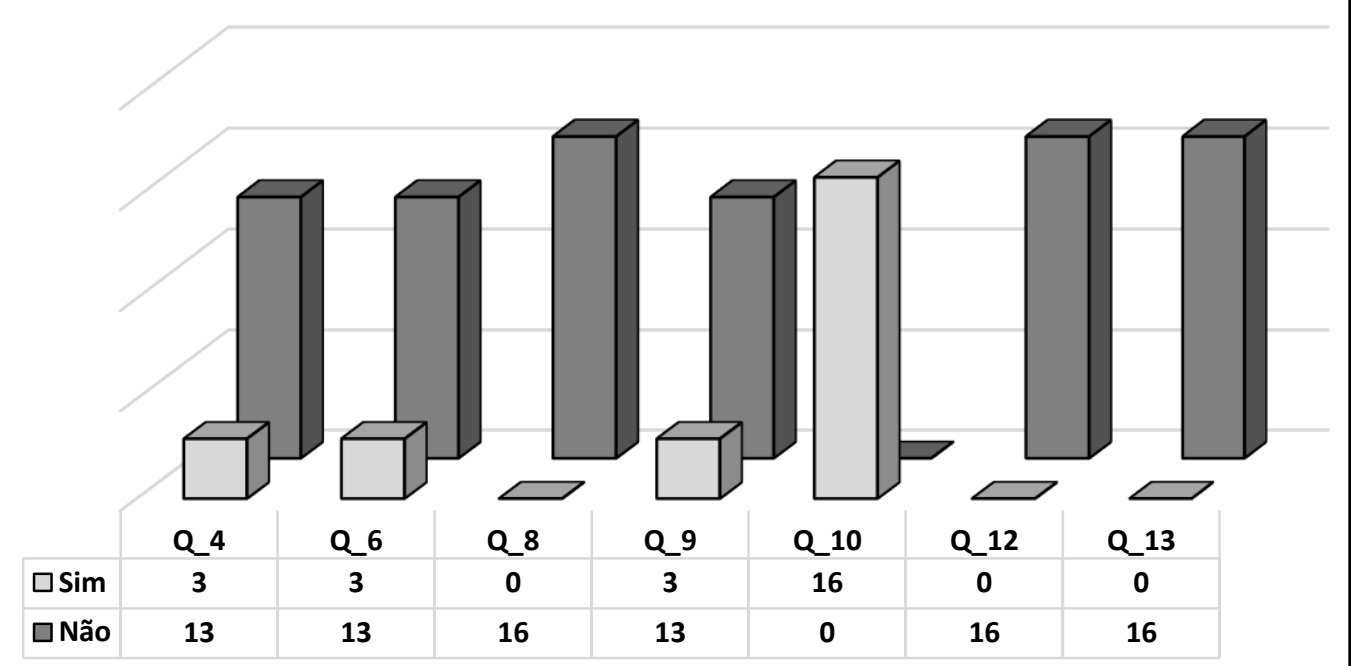

Figura 5: Questão_4. Dor, formigamento ou dormência, Questão_6. Dificuldade para realizar o trabalho, Questão_8. Receber por produção, Questão_9. Fazer horas extras, Questão_10. Utilizar equipamento de segurança, Questão_12. Ouviu falar em DORT, Questão_13. Conhece alguém que teve essa doença. 
No que se refere a como os trabalhadores se sentem na realização de seu trabalho na Pedreira (Questão_7), 6,25\% (n=1) se sente "ótimo", 68,75\% (n=11) respondeu que se sente "bem" e 25\% (n=4) têm dificuldades ou não souberam responder (Figura 6).

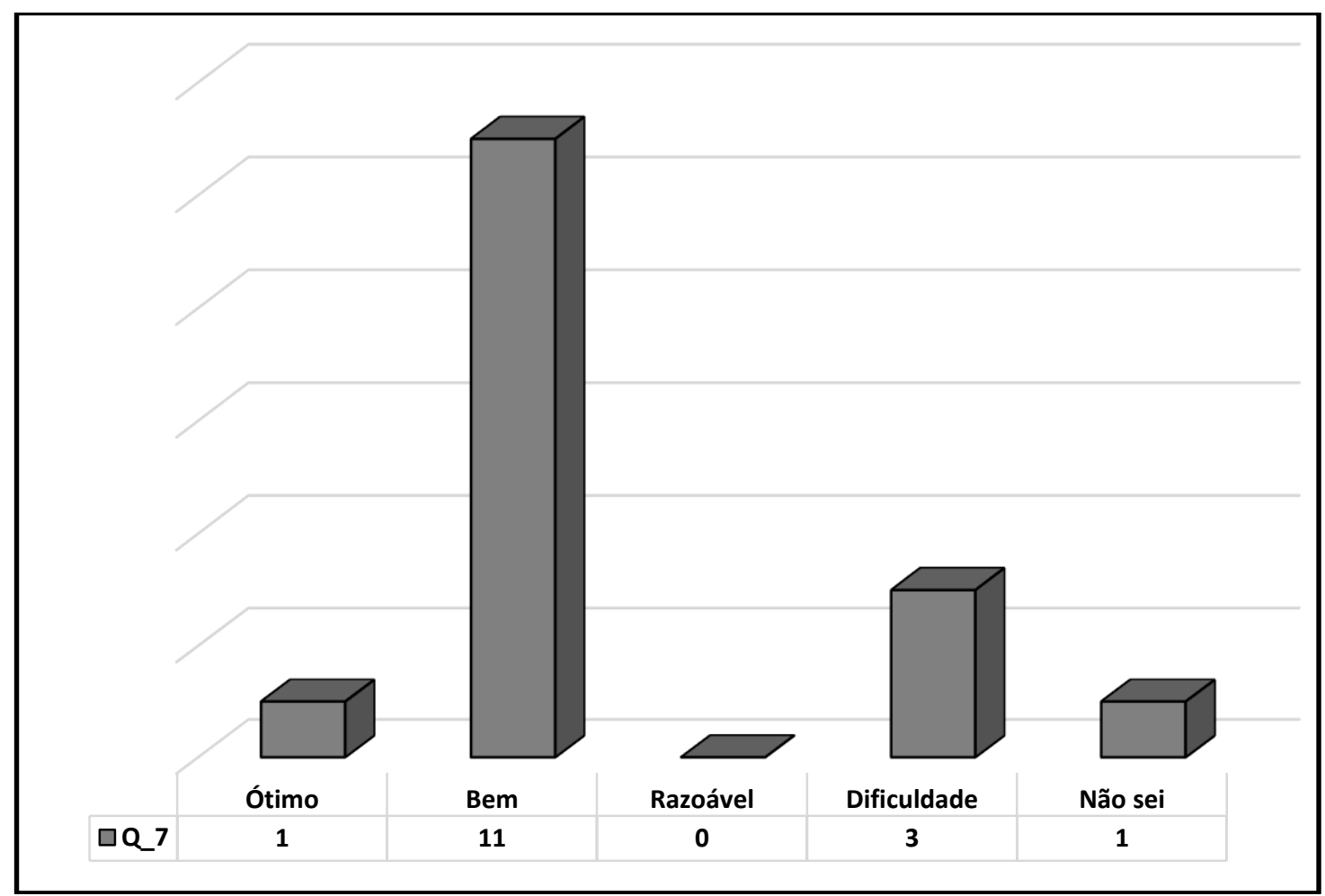

Figura 6: Questão 7. Como é seu desenvolvimento na realização do trabalho?

Os trabalhadores da faixa etária de 40-59 anos 50\% (n=3) apresentaram dor nas costas (Questão_1_4, p-valor 0,04, r=0,27) (Figura 7).

Os $18,75 \%(n=3)$ dos trabalhadores que apresentaram queixa de dor nas costas tinham mais de 28 anos de trabalho na Pedreira (Questão_2_6, p-valor 0,04, r=0,27) (Figura 7). 


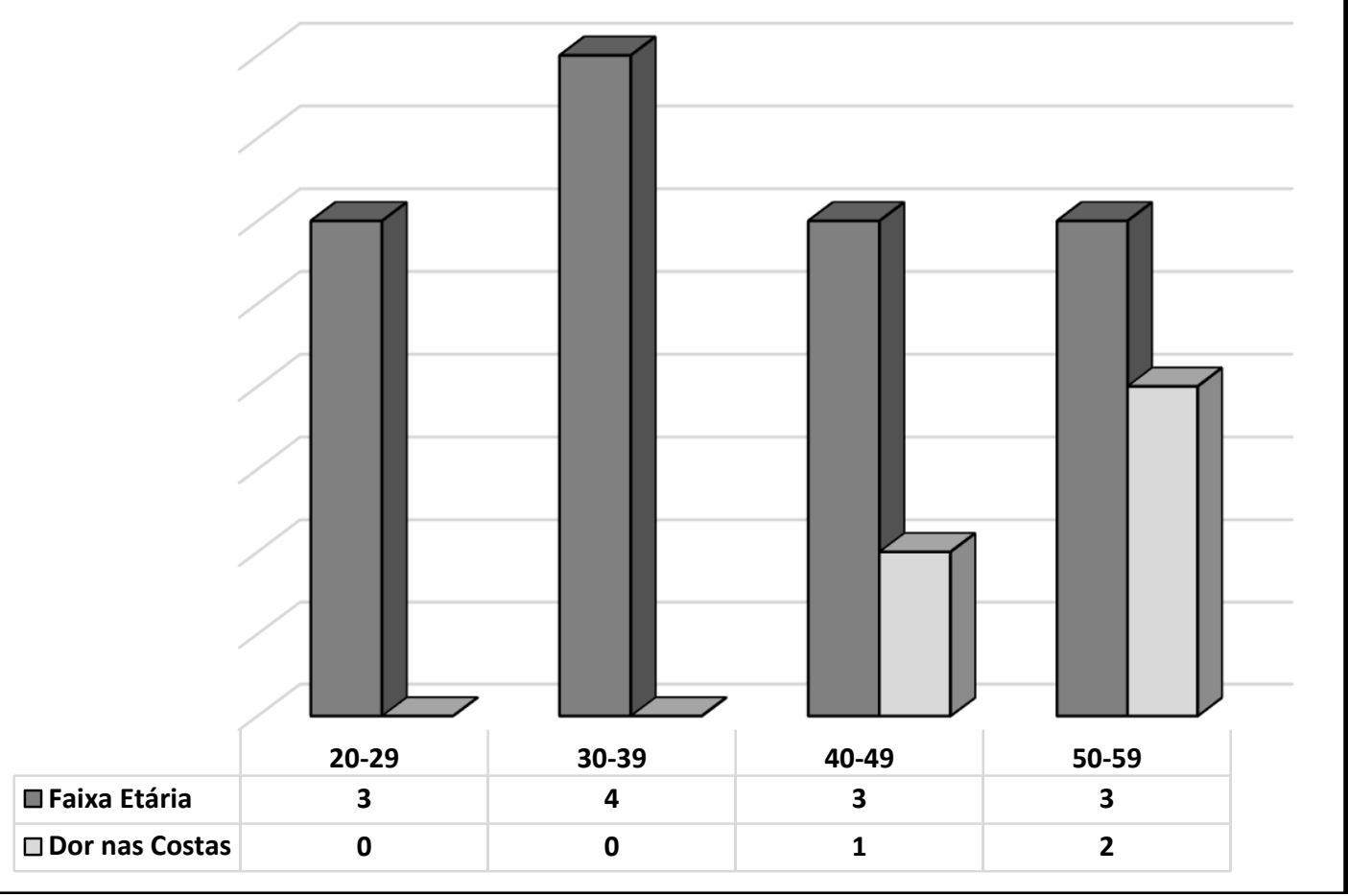

Figura 7: Relação faixa etária e dor nas costas

\section{DISCUSSÃO}

Este estudo teve por finalidade identificar o conhecimento dos trabalhadores de pedreira sobre a doença ocupacional (DORT) e seus mecanismos de prevenção.

No decorrer dos anos o trabalho em empresas, escritórios, fábricas, pedreiras entre outros; vem se aperfeiçoando e, com isso, aumentando em intensidade e em número de obrigações de seus trabalhadores, consequentemente, acarretando alguma doença ocupacional, mais precisamente, DORT (Distúrbio Osteomuscular Relacionado ao Trabalho). Percebe-se assim que a competividade no trabalho, a adoção de horas-extras e/ou o estímulo do trabalho por produção são causas que levam à DORT (CHIAVEGATO FILHO \& PEREIRA JR.). Em nosso estudo os trabalhadores declararam trabalhar 48 horas, mas apenas três confirmaram receber horas extras (NOVAES, 2017).

Os distúrbios osteomusculares relacionado ao trabalho (DORT'S), denominado até uns anos atrás como lesões por esforços repetitivos (LER). Foi editado pelo Instituto Nacional de Previdência Social (INSS) por ser percebido que as doenças ocupacionais em questão apresentadas em trabalhadores eram dores crônicas que nem sempre causavam lesões. O DORT é uma doença ocupacional causada pelo esforço repetitivo, podendo ser acometido por estresse, esforço muscular, falta de postura, repetição de tarefas entre outras pressões que promovem a sobrecarga das condições físicas. Consta no INSS (1998), DORT caracterizada como uma síndrome clínica onde há dores osteomusculares crônicas seguidas ou não de alterações objetivas, 
que acabam se manifestando no pescoço, na cintura escapular e/ou em membros superiores no caso de ter sido agravada pelo trabalho (TEIXEIRA, 1998).

O DORT é uma doença que precisa ter diagnostico breve e ser tratada com remédios, fisioterapia, em alguns casos, atendimento psicológico. O paciente, na maioria dos casos, sentese intimidado, incapaz, com dor, formigamento e/ou dormência. O trabalhador em questão necessita do apoio familiar, a compreensão do empregador e o auxílio de uma equipe médica especializada para amenizar a dor e auxiliar na sua reabilitação (OLIVEIRA \& FREITAS, 2001).

DORT pode ocorrer com maior frequência nos tendões, músculos, nervos, coluna, membros superiores, pescoço. No entanto, independente da região do corpo, qualquer uma pode ser afetada por DORT, basta que sejam expostas a mecanismos de traumas contínuos (BRUNA VARELLA, 2011). Assim, essa síndrome pode se manifestar em regiões como a coluna lombar quando a pessoa carrega peso excessivo ou faz longas caminhadas e corridas, pois a carga exercida sobre é maior e se torna muito repetitiva (BRUNA VARELLA, 2011).

Todo trabalhador que realiza suas atividades em ritmo acelerado, que não tem pausa, carga horária excessiva, com uma postura inadequada e sobrecarga de peso deve-se preocupar em usar EPI adequado. Em nosso estudo um dos sintomas de DORT relatados com maior frequência foi a queixa de dores nas costas como descrito na fala de um trabalhador quando foi perguntado: Q.4:“Sente dor em alguma parte do corpo?”, T.1, fragmento 1: “Nas costas, todos nos sentimos, pois pegamos mais de 50 quilos por vez". No entanto, a maioria dos respondentes quando questionados se sentiam algum problema em alguma parte do corpo e se "alguma vez foi impedido ou teve dificuldade de realizar algum tipo de tarefa por sentir dor? (Questão 7) 81,25\% responderam que não para ambas as questões.

O aumento dos casos de DORT, segundo Couto, está associado à quantidade de operários vulneráveis; aos trabalhos exercidos sobtensão excessiva; à má gestão de toda a produção, à anulação de processos exercidos que possam prejudicar o operário, como pausas e tempos improdutivos que exercem a favor da prevenção de fadigas e recuperação devido ao trabalho e esforço exercido (DUNCAN, 2013).

A análise dos resultados do questionário permitiu identificar o percentual dos trabalhadores que sentem algum tipo de dor, a existência de alguma doença ocupacional e seu conhecimento acerca da prevenção, sintomas e tratamento do DORT (Questão_1_4, p-valor 0,04, r=0,27; Questão_2_6, p-valor 0,04, r=0,27) e mostrou também que os trabalhadores da pedreira desconheciam o significado do termo DORT como uma doença.

Segundo Rosa et al. (2008), para evitar DORT, os trabalhadores de pedreiras deveriam conhecer a utilização correta do equipamento de proteção como: cinta lombar, luvas, calçados apropriados e receber orientação quanto ao cuidado com a postura, exercícios de alongamento e fortalecimento da musculatura e os empregadores estabelecer períodos de pausa do trabalho e, se 
possível, a utilização de guindaste para levantar as rochas mais pesadas. Percebe-se o risco do trabalhador em adquirir DORT pelo desenvolvimento de suas atividades, em nosso estudo, $25 \%$ apresentou dificuldade de desenvolver suas atividades.

Quando a DORT é identificada em trabalhadores, como os que foram entrevistados em nosso estudo, suportando diariamente um peso excessivo (+ de 50 quilos) por 48 horas semanais, carga horária superior ao estabelecido pelo artigo 58 da Consolidação das Leis Trabalhistas (CLT) o mesmo deve ser afastado da função e ser submetido a tratamento com medicamentos e fisioterapia. O paciente passa a necessitar de cuidados permanentes, nas fases mais avançadas, pode vir a precisar do uso de corticoides e intervenção cirúrgica, sem contar que o indivíduo pode entrar em processo depressivo (MERLO et al, 2001).

Estes são fatores que dificultam a identificação e prevenção de DORT pelos empregadores e trabalhadores, o primeiro, pelo aumento de custo da produção, o segundo pelo risco de perder o emprego, não buscam tratamento nem esclarecimento sobre os meios de prevenção.

\section{Conclusão}

Através desta pesquisa pode se concluir que os trabalhadores da pedreira desconhecem DORT e o mais preocupante é que desconhecem os mecanismos de prevenção. Deve-se consciencializar todos os trabalhadores sobre a importância da postura e do uso permanente de EPI a fim de amenizar a incidência de casos.

A pesquisa permitiu orientar os trabalhadores sobre DORT e esclarecer que a falta de força não significa incapacidade, mas a necessidade de diagnóstico o mais rápido possível de suas causas e medidas preventivas.

\section{Referências}

BARBOSA, M. S. A.; SANTOS, TREZZA, R. M.; FIGUEIREDO, M. C. S. A vida do trabalhador antes e após a Lesão por Esforço Repetitivo (LER) e Doença Osteomuscular Relacionada ao Trabalho (DORT). Rev. bras. enferm. [online]. 2007, vol.60, n.5, pp.491-496. ISSN 00347167. http://dx.doi.org/10.1590/S0034-71672007000500002.

BRUNA VARELLA, M. H. Lesões por esforços repetitivos (L.E.R. / D.O.R.T.). Disponível em: $<$ https://drauziovarella.com.br/letras/l/lesoes-por-esforcos-repetitivos-1-e-r-d-o-r-t/>. Acesso em: 24 jul. 2017. 
CHIAVEGATO FILHO, L. G.; PEREIRA JR., A. Work related osteomuscular diseases: multifactorial etiology and explanatory models, Interface - Comunic., Saúde, Educ., v.8, n.14, p.149-62, set.2003-fev.2004.

DUNCAN, B. B.; SCHMIDT, M. I.; GIUGLIANI, E. R. J. DUNCAN, M. S.; GIUGLIANI, C.; Medicina ambulatório: Condutas de atenção primária baseadas em evidencias. $4^{\mathrm{a}}$ ed. Editora Artmed, p.1294-1306, 2013.

MERLO, A. R. C.; JACQUES, M. G. C. \& HOEFEL, M. G. L. Trabalho de Grupo com Portadores de Ler/Dort: Relato de Experiência. Psicologia: Reflexão e Crítica, 2001, 14(1), pp 253-258.

MONTEIRO, A. L.; BERTAGNI, R. F. S. Acidentes do Trabalho e Doenças Ocupacionais: conceito, processos de conhecimento e de execução e suas questões polêmicas. 2. ed. Editora Saraiva, p. 60-75, 2000.

NOGUEIRA, R.; BENETTI; F. A. Principais queixas osteomusculares em músicos da região do ABC paulista: um estudo de prevalência. ABCS Health Sci. 2016; 41(1):40-45. DOI: http://dx.doi.org/10.7322/abcshs.v41i1.844.

NOVAES, A. C. Histórico de o fenômeno LER/DORT. Disponível em: <https://www.lerdort.com.br/editorial/82/conceitos-gerais/historico-do-fen-meno-ler-dort>. Acesso em: 25 jul. 2017.

OLIVEIRA, R. M. R.; FREITAS, C. M. A abordagem das lesões por esforços repetitivos/distúrbios osteomusculares relacionados ao trabalho - ler / dort no centro de referência em saúde do trabalhador do Espírito Sant, 2001 - crst/es.. Disponível em: https://www.arca.fiocruz.br/handle/icict/5091. Acesso em: 25 jul. 2017.

RAMAZZINI, B.; As doenças dos trabalhadores; tradução de Raimundo, E.; Morbis, A. D. 4. ed. Editora São Paulo, p.299-310, 2016.

ROSA, A. F. L; GARCIA, P.; ALMEIDA, T. V.; CAMPOS, R. G.; LOPES, M. S. Incidência de LER/DORT em trabalhadores de enfermagem. Acta Sci. Health Sci. Maringá, v. 30, n. 1, p. 19$25,2008$.

TEIXEIRA, M. J. Dor: manual para o clinico. Editora Atheneu, p. 401-410, 2007. 